nothing that distresses the patient; because, with a hopeless outlook, this is the correct treatment.-I am, etc.,

ANTHONY GreEN

Department of Radiotherapy,
Royal Northern Hospital,

Royal Northe

1 Green, A., British Medical fournal, 1966, 2, 951.
2 Spittle, M. F., and Newton, K. A., British fournal
of Cancer, in press. of Cancer, in press.

and Ovary, p. 188. Chicago, Year Book Medical Publishers, 1969.

Green, A., Proceedines of the Royal Society of
Medicine, 1954. 47, 907.

Radio'o., Barshaw, M. A.,

6 Green, A., Lancet, 1965, 1. 276.

7 Green, A., Na'uro, 1965. j07, 1311. 1969. 4. 622.

Green, A., British Medical fourna!, 1969, 4. 622.
Baoshawe, K. D.. Goldino, P. R., and Orr, A. H
British Medical fournal, 1969, 3, 733 .

\section{Prolonged Therapeutic Starvation in Gross Refractory Obesity}

SIR,-The poor long-term prognosis of therapeutic starvation, its hazards, and prolonged hospitalization implied by Dr. J. F. Munro and colleagues in their article (19 December, p. 712) prompts me to suggest the alternative use of intestinal shunt in suitable cases of gross intractable obesity. This oneration has been used for more than ten years by Payne and DeWind ${ }^{1}$ and others in the U.S.A. Personal experience with this procedure is illustrated by the following case report.

The patient was a 46-year-old mother of three children, who had been dieting for three years. Durine that period she had gained $7 \mathrm{lb}$ $(3 \mathrm{~kg})$ in weight to $274 \mathrm{lb}(124 \mathrm{~kg})$. Her height is 62 in $(2.1 \mathrm{~m})$. She presented because she was ashamed of her gross appearance and because of shortness of breath, backache, and poor mobility. She had lost her job four months prior to admission to hospital in February 1970 because of the latter.

Physical examination revealed no other relevant abnormality, apart from her gross generalized obesity. She was an extroverted, pleasant woman, who readily stated her preparedness to undergo any procedure which would reduce her weight. Preoperative biochemical investigations (serum electrolvtes, urea, glucose, calcium. magnesium, iron and binding capacity, cortisol, protein bound iodine, vitamin $B_{12}$ and folate) were normal. apart from the serum cholesterol (260 $\mathrm{me} / 100 \mathrm{ml}$ ). Urinary steroids, creatinine clearance, and electrocardiogram were all normal.

On 18 February 1970 I performed a jejunoileostomy. The jejunum was divided 14 in $(35.5 \mathrm{~cm})$ from the duodeno-jejunal junction and the proximal end anastamosed end-to-side to the ileum 4 in $(10 \mathrm{~cm})$ from the ileo-caecal valve. The free end of jejunum was closed and anchored to the base of the mesentery to prevent intussusception. Her postoperative recovery was marred only by a mild degree of wound sepsis and she was discharged home on the sixth postoperative day, weighing $266 \mathrm{lb}$ (121 kg).

During the ensuing ten months she has lost weight steadily to $196 \mathrm{lb}(89.1 \mathrm{~kg})$ in December 1970. There has been no evidence of psychological disturbance, and she is delighted with the result. Her breathlessness and backache in particular have remitted, and she is totally free of the dietary worries which have plagued her for many years. She eats with impunity steak chips, fatty, and other high-calorie foods until satiated, and there has been at no time any problems of diarrhoea. Her only difficulty has been in flushing down the lavatory her once daily fatty stools. The three-day faecal fat output is $25.8 \mathrm{~g}$, and the only other biochemical abnormalities which have come to light at her regular monthly examinations have been a fall in serum albumin from a preoperative mean of $4.4 \mathrm{~g} / 100 \mathrm{ml}$ to $3.6 \mathrm{~g} / 100 \mathrm{ml}$, and the serum iron, which now ranges from 60 to $80 \mu \mathrm{g} / 100$ $\mathrm{ml}$. Serum cholesterol has declined to 17 $\mathrm{mg} / 100 \mathrm{ml}$. Her only medication throughout the postoperative period has been iron and multivitamin therapy.

The result to date has been very satisfactory, and there appears to be no need to reverse the intestinal short circuit. It is planned to admit her to hospital again in January 1971 for full metabolic reassessment prior to removal or her large fatty apron and repair of an old nephrectomy incisional hernia.

A hazard of jejuno-ileal shunt appears to be a psychiatric disturbance, usually a depressive state, seen in a small number of patients. For this reason the selection of patient for the operation should include a ful psychiatric assessment. Otherwise, potential complications such as intussusception volvulus, and metabolic deficiencies can be prevented by care at operation and by regular postoperative monitoring. Diarrhoea is not usually a problem as the ileocaecal valve is not bypassed.

Though physicians express some scepticism and reluctance to recommend operative treatment of gross intractable obesity, there is little doubt that in well selected patients this quite simple operation is a very effective and rewarding form of management.am, etc.,

General Hospital,

Michael Badeley

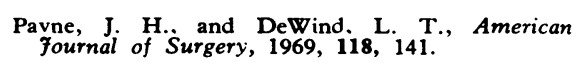

\section{Penicillin Instability in Infusions}

SIR,-YYour leading article (5 December 1970 , p. 571) drew attention to the important questions of drug stability in intravenous infusion solutions and of possible chemical interaction between drug which are added to such infusions. This is undourbtedly an area where a good deal more research is needed.

Detailed information on the stability of the semisynthetic penicillins in eight infusion solutions was published earlier this year. ${ }^{1}$ Furthermore, in conjunction with colleagues in hospital pharmacy, we are at present engaged on an extensive programme of assays to study the effects of mixing other drugs with penicillins in a range of intravenous media. Such assays are essential for the detection and measurement of interactions, which are often unaccompanied by visual changes. For example, methicillin undergoes $15-20 \%$ inactivation in five minutes when mixed with kanamycin at intramuscular concentrations, though the solution remains clear. We have also found that ampicillin, methicillin, and carbenicillin should not be added to dextrose or saline infusions containing $0.02 \%$ hydrocortisone sodium succinate, though cloxacillin is unaffected by the latter.

Your article also discussed a recent paper which reported accelerated decomposition of several penicillins in solutions of carbohydrate buffered to $\mathrm{pH}$ 8.5-8.9 with 0.05 or $0.075 \%$ sodium bicarbonate compared with solutions of carbohydrate or bicarbonate separately. ${ }^{2}$ As far as I am aware, the use of mixed dextrose/bicarbonate solutions is unusual in Britain, so that the observed effect, though interesting, if of marginal relevance to routine infusion practice. The inactivation was also accentuated by the fact that the experiments were performed at $37^{\circ} \mathrm{C}$ rather than at room temperature Ampicillin should in case be infused within four hours in dextrose or dextrose saline, and methicillin within five to six hours, though carbenicillin, cloxacillin, and flucloxacillin are very stable in these media. Carbenicillin and methicillin are relatively stable in $1.4 \%$ sodium bicarbonate solution, but ampicillin should be infused within six hours and cloxacillin within eight hours in this fluid. -I am, etc.

BRIAN LYNN

Head of Medical Informat:on and Services Beecham Pharmaceutical Division, Brentford, Middx

Lynn, B., Fournal of Hospital Pha:macy, 1970 Simberk off, M. S. Thomas. L. McGregor, D.
Shonkein, I., and Levine, B. B. New England Shrnkein, I., and Levine, B. B. New Enzland
fou nal of Medicine, 1970, 283, i16.

\section{Diabetic Ketoacidosis and Influenza}

SIR,-Having recently encountered a patient reminiscent of cases reported by Dr. P. J Watkins and others (10 October, p. 89), we wish to submit a brief report

A 23-year-old woman was admitted with a five-day history of severe cough and malaise followed by nausea, vomiting, and diarrhoea for 24 hours prior to admission. Her blood pressure was $100 / 40$, pulse 168 , respiration rate 40 . She was confused and her face was flushed. An acetone breath was noted.

Blood sugar was $709 \mathrm{mg} / 100 \mathrm{ml}$, sodium $147 \mathrm{mEq} / 1$, potassium 3.5 , chloride $111, \mathrm{CO}$ content 15, pH 7.20, and $\mathrm{PCO}_{2} 36.4 \mathrm{~mm} \mathrm{Hg}$. Two hours after the blood was drawn for these determinations cardiac arrest occurred. She had received 120 units of insulin, $45 \mathrm{mEq}$ of sodium bicarbonate, and 11 . of normal saline. The patient did not recover. Chest $x$-ray films were nggative. An E.C.G. had revealed supraventricular tachvcardia of 200 per minute. Peaked P waves that merged with tall $T$ waves were present. The course of events suggests that the patient succumbed to hypokalemia. There was no previous history of diabetes mellitus.

The $\mathrm{PCO}_{2}$ was higher than expected for a simple metabolic acidosis. All four of the patients with $\mathrm{PCO}_{2}$ values reported in the paper by $\mathrm{Dr}$. Watkins and his colleagues presented respiratory insufficiency superimposed on metabolic acidosis. Blood $\mathrm{pH}$ of 13 of their 29 patients was less than 7.1. Such severe acidosis may have been the result of inadequate respiratory compensation in diabetic ketoacidosis.

This suggests to us the possibility that severely depleted total body potassium whatever its cause, may prevent adequate respiratory compensation in metabolic acidosis. Special attention should be directed to serum potassium levels in diabetic ketoacidosis when $\mathrm{PCO}_{2}$ values are higher than expected for a pure metabolic acidosis.-We are, etc.,

Charles K. Tashima IVo KaLACIC Danilo Deano

Department of Medicine,

Chicago, Ill., U.S.A 